\title{
Urdimento
}

Revista de Estudos em Artes Cênicas

E-ISSN: 2358.6958

\section{Teatro na Prisão: A Extensão e a Pesquisa como caminhos formativos em Pedagogia do Teatro}

\author{
Andressa da Silva Santos \\ Emerson de Paula Silva
}

\section{Para citar este artigo:}

SANTOS, Andressa da Silva; SILVA, Emerson de Paula. Teatro na Prisão: A Extensão e a Pesquisa como caminhos formativos em Pedagogia do Teatro. Urdimento, Florianópolis, v. 3, n. 39, nov./dez. 2020.

DOI: http:/dx.doi.org/10.5965/14145731033920200117

Este artigo passou pelo Plagiarism Detection Software | iThenticate 


\title{
Teatro na Prisão: A Extensão e a Pesquisa como caminhos formativos em Pedagogia do Teatro
}

\author{
Andressa da Silva Santos ${ }^{1}$ \\ Emerson de Paula Silva²
}

\begin{abstract}
Resumo
Este relato refere-se a uma experiência discente junto a uma ação de extensão e a um projeto de pesquisa sobre Teatro e Educação Penitenciária promovido pelo Curso de Licenciatura em Teatro da Universidade Federal do Amapá - UNIFAP. Procuramos discorrer sobre a participação junto ao projeto temático e como a prática extensionista se transformou em investigação científica sobre a relação do fazer teatral junto ao espaço prisional e o reflexo destas ações na formação discente/docente dos licenciandos do curso em questão.
\end{abstract}

Palavras-chave: Teatro. Prisão. Extensão. Pesquisa.

\section{Theater in Prison: Extension and Research as formative paths in Theater Pedagogy}

\begin{abstract} of the course in question.

Keywords: Theater. Prison. Extension. Search.
\end{abstract}

This report refers to a student experience with an extension action and a research project on Theater and Penitentiary Education promoted by the Theater Degree Course at the Federal University of Amapá - UNIFAP. We tried to discuss the participation with the thematic project and how the extension practice became a scientific investigation on the relationship of doing theater with the prison space and the reflection of these actions in the student / teacher training of the undergraduates

\footnotetext{
${ }^{1}$ Licencianda em Teatro na Universidade Federal do Amapá - UNIFAP. Bolsista Iniciação Científica NECID PROBIC - UNIFAP. Integrante do Projeto de Extensão Teatro e Prisão: Ressocialização Através da Arte - PROEAC - UNIFAP. andressatroye@gmail.com

2 Professor do Curso de Teatro da Universidade Federal do Amapá (UNIFAP). Doutorando em Estudos Literários (UNESP). Mestre em Artes da Cena pela UNICAMP, Licenciado em Artes Cênicas pela UFOP. emersondepaulaubuntu@gmail.com
} 
Teatro en prisión: extensión e investigación como vías formativas en la pedagogía del teatro

\section{Resumen}

Este informe se refiere a la experiencia de un estudiante con una acción de extensión y un proyecto de investigación en Teatro y Educación Penitenciaria promovido por la Licenciatura en Teatro de la Universidad Federal de Amapá - UNIFAP. Intentamos discutir la participación con el proyecto temático y cómo la práctica de extensión se convirtió en una investigación científica sobre la relación del hacer teatro con el espacio carcelario y el reflejo de estas acciones en la formación alumno / docente de los estudiantes de la carrera en cuestión

Palabras Clave: Teatro. Prisión. Extensión. Buscar. 
Este relato refere-se à experiência junto ao grupo de pesquisa NECID Núcleo de Estudos em Espaços Culturais, Inclusivos e Deliberativos - vinculado ao CNPq e ao Departamento de Pesquisa (DPQ) da Universidade Federal do Amapá UNIFAP. Tal grupo é liderado pelo Professor Assistente Emerson de Paula do Curso de Licenciatura em Teatro da UNIFAP e procura investigar, através da linha temática Teatro e Educação Penitenciária, processos formativos de uma prática pedagógica inclusiva nas Artes da Cena através de projetos de extensão e pesquisa relativos à área em questão, propostos pelo docente líder do referido grupo.

Neste sentido, buscamos registrar o processo de vivência nesta experiência de pesquisa extensionista e o seu impacto em nossa formação discente/docente.

\section{Projeto de Extensão}

O projeto Teatro e Inclusão: Ressocialização Através da Arte é realizado desde 2017, mas neste relato será contextualizado o período de 01/02/2018 a 31/01/2019. Tal iniciativa realizou oficinas de Teatro junto ao Instituto de Administração Penal de Macapá (IAPEN/AP) analisando de forma teórica e prática o Teatro/Educação como linguagem capaz de contribuir com a promoção da cidadania para pessoas em situação de cárcere e/ou vulnerabilidade social e com seu processo de ressocialização na comunidade. Para tanto pretendeu-se potencializar a linguagem teatral como estimuladora da fruição estética a este público construindo ainda metodologias e materiais para este fim. Este projeto dialogou com o PROCULT Programa de Cultura da UNIFAP.

A partir de diagnóstico preliminar das ações já desenvolvidas em 2017 pela primeira equipe do projeto e por proposição das/dos próprias/próprios apenadas/apenados participantes à época, propomos na nova etapa de realização, a continuidade de uma oficina de Teatro no intuito de aplicar a metodologia de trabalho com o Teatro/Educação como contribuição enquanto processo educativo e cidadão na ressocialização dos/das apenado/as. Procuramos ainda discutir a área de Teatro e Educação Penitenciária que busca a inclusão de grupos excluídos como protagonistas em ações artísticas, potencializando o Teatro/Educação como 
importante metodologia de transformação social.

Esta ação dialogou com o Projeto Pedagógico do Curso de Teatro da UNIFAP devido à presença da disciplina Estágio Supervisionado $\vee$ que propõe o contato do/a licenciando/a em Teatro com outros espaços para além da escola, potencializando a discussão entre Artes da Cena e Comunidade, o que gera uma experiência real com a comunidade local, induzindo nos/as discentes envolvidos/as a experiência extensionista gerando impacto direto em sua formação enquanto agentes transformadores da realidade, estimulando o aprendizado acadêmico mas também cidadão.

O trabalho dentro do ambiente escolar presente no sistema prisional se deu por este local já possuir um grupo focal capaz de atender as investigações iniciais do projeto. O trabalho inicial com o grupo que frequenta a Escola procurou averiguar o estudo do Teatro em diferentes espaços e como este ressignifica a leitura dos mesmos. Após avaliação deste momento e da participação deste grupo, o trabalho poderia ser ampliado à população carcerária geral não participante da Escola. Portanto, abordamos aqui não só a presença do Teatro dentro/nas prisões, mas o Teatro dentro dos espaços escolares existentes nas instituições prisionais por entendermos que:

Numa proposta de inversão do controle instituído na escola, como um mote para a transgressão deste processo civilizador, propusemos, artisticamente falando, uma iniciação estética através do Teatro junto a Escola instalada na Penitenciária de Macapá, no sentido de possibilitar mecanismos de redescoberta do prazer e de constituir, no espaço escolar, um ambiente de troca, de experiência e de formação pelo sensível. A presença da instituição escolar dentro da prisão contribui de certa forma para uma quebra em alguns pressupostos sobre estas instituições, pois provoca reflexões em relação a alguns aspectos anteriormente mencionados. Nesse contexto, levar o Teatro à Educação Penitenciária é potencializar momentos de apreciação estética e criação artística individual e coletiva no campo da Arte/Teatro como recurso de encontro para potencializar a autonomia e a sensibilidade no contexto escolar prisional. (Silva, ... [et al.], 2020, p. 119).

Neste projeto, tomamos por tema as limitações e restrições à participação de pessoas em situação de cárcere em ações culturais a partir das pesquisas da 
Profa. Dra. Eliane Vasquez(2015), refletindo a partir destes estudos sobre os aspectos que impedem ou dificultam a participação destas pessoas nas ações culturais, registrando os vários olhares e realidades existentes e possíveis de modificação através das oficinas de Teatro. Nesta perspectiva, são as metodologias de Paulo Freire (1987) sobre a Pedagogia do Oprimido, juntamente com a metodologia do Teatro/Educação proposta por Viola Spolin (2010) e seu sistema dos jogos teatrais que subsidiaram a parte prática e pedagógica das ações realizadas pelo projeto. As pesquisas realizadas no Brasil desenvolvidas pelo Prof. Dr. Zeca Ligiéro (1983) sobre Teatro e Comunidade e as pesquisas sobre os dilemas do Teatro na Prisão desenvolvidas pelo Prof. Dr. Vicente Concílio (2006) subsidiaram também as temáticas e exercícios a serem trabalhados nas aulas semanais nos respectivos espaços.

O projeto realizou oficinas semanais junto ao IAPEN - MACAPÁ (Masculino e Feminino). O espaço de atuação foi a Escola Estadual São José localizada dentro da instituição gerenciada pela Secretaria de Estado da Educação - EESJ/SEED. As aulas aconteceram junto à disciplina Arte tendo acompanhamento da professora responsável que promoveu uma observação participativa. As aulas eram de 50 minutos e as turmas possuíam 2 aulas de Arte por semana. Neste sentido, a primeira aula de cada turma passou a ser dedicada ao estudo da linguagem artística do Teatro contando com profissionais da área específica (a equipe do Projeto) e a aula subsequente era dedicada a linguagem artística das Artes Visuais orientada pela docente responsável pela disciplina Artes na referida Escola. Entretanto, a docente em questão construiu um planejamento conjunto com o projeto propondo, em suas aulas, uma contextualização sobre o que fora vivenciado na aula de Teatro e como as temáticas possuíam diálogos com/nas Artes Visuais. A questão do corpo como um veículo de comunicação se apresentou por exemplo, como um conteúdo explorado nas aulas em geral. Foram ao todo 6 turmas: 4 no IAPEN Masculino e 2 no IAPEN feminino tendo própria sala de aula de cada turma como espaço de trabalho.

Nesta ação direta com uma parcela da sociedade tivemos como objetivo democratizar o acesso ao Teatro e ao direito a Cultura. Após 6 meses de realização 
desta ação, ampliamos o olhar investigativo que esta prática extensionista proporcionava e iniciamos um processo de pesquisa junto ao PROBIC - UNIFAP sob orientação também do docente coordenador do projeto de extensão.

Buscamos entender junto ao projeto de pesquisa como o Teatro poderia contribuir para com a transformação de diferentes ambientes em espaços de criação artística pesquisando as interfaces das Artes da Cena como elemento de ressignificação da instituição prisional a partir da análise das metodologias e propostas de intervenção realizadas na prática extensionista aqui relatada.

\section{O Projeto de Pesquisa}

A pesquisa intitulada Espaço Prisional como Espaço de Criação Artística pretendeu analisar o impacto da realização das oficinas do projeto extencionista Teatro e Inclusão: Ressocialização Através da Arte promovidas pelo Curso de Teatro da UNIFAP junto ao IAPEN - Macapá investigando como o fazer teatral poderia contribuir na ressignificação de diferentes espaços potencializando ambientes não convencionais de estabelecimento da Arte como espaço de criação artística. Este projeto estava vinculado também ao Projeto de Pesquisa Políticas Públicas para a Educação Penitenciária no Amapá: Por uma implantação de Programa Governamental cadastrado junto DPQ - UNIFAP coordenado pela Profa. Dra. Eliane Leal Vasquez. Pelo grupo de pesquisa NECID, este plano de trabalho investigativo fez parte da pesquisa sobre o Teatro na promoção de espaços culturais, inclusivos e deliberativos.

O projeto tinha como premissa que o espaço na linguagem teatral é algo amplo, entendendo o corpo como primeiro espaço a ser habitado e que há diálogo deste corpo nos diferentes espaços que este mesmo ocupa. Portanto, a pesquisa agregou os múltiplos olhares que o Teatro poderia proporcionar a diferentes sujeitos a partir da ampliação da geografia do olhar no que tange entender as potencialidades da presença do fazer teatral para além do espaço de Arte.

A discussão investigativa tinha como trilha ainda averiguar como o fazer teatral potencializa aprendizados capazes de serem transpostos para a vida diária, 
contribuindo com pesquisas na área da Pedagogia do Teatro entendendo ainda que o direito a Cultura é necessário a todo e qualquer ser humano. Neste sentido, buscou-se entender que o espaço prisional poderia ser também um espaço de criação artística e não de reprodução artística e como este processo poderia ser motivador de ações de ressocialização.

\section{O Sistema Penitenciário do Amapá: teoria x prática}

O sistema penitenciário em geral possui em si critérios rigorosos e os/as apenados/as tendem a se adaptar às regras impostas por ele. Existem apenados/as que possuem obrigações e estão encarregados/as de algumas funções junto ao sistema. Uns/umas limpam os dormitórios e a escola, outros/as trabalham na manutenção física das instalações, outros/as são encarregados/as de trabalhar na cozinha. Esta divisão de tarefas acontece tanto no espaço prisional feminino como no masculino.

Vasquez (2015) realizou várias pesquisas com ex-alunos apenados do IAPENAP e desenvolveu um método de conversa com estes apenados buscando entender como é a promoção da cultura escolar e como é a realidade das regras de convivência da prisão (criadas por apenados) e das regras de conduta do sistema penitenciário. Em nosso projeto de extensão, durante as improvisações propostas, vários/as alunos/as relataram sobre a realidade do sistema da prisão, da cela, as formas de linguagem, suas normas de convivência, práticas prisionais, sistemas de viração e a produção de peças de artesanatos, contato mais específico relacionado pelos/as participantes com o fazer artístico-cultural no espaço prisional.

Durante as aulas ministradas no complexo penitenciário do Amapá, percebemos a diferença da prática para com a teoria uma vez que constatamos que o sistema penitenciário é realmente constituído por duas leis: as leis de dentro da prisão e as leis do próprio sistema penitenciário, que possuem diferenças discrepantes e perceptíveis entre si. Neste sentido, trabalhar com o sistema teatral spoliniano de jogos de regras oportunizou o estabelecimento de um código único para que a proposta, que tinha como premissa a participação voluntária, 
acontecesse de forma eficaz e promotora de uma aprendizagem de vida uma vez que, é possível viver a liberdade ainda que dentro de uma sociedade tão regrada. Regras são reformuladas se necessário e passíveis de transformações se for da vontade de todos num grupo, numa comunidade uma vez que:

Na instituição lúdica, a regra pressupõe processo de interação. O sentido de cooperação leva ao declínio do misticismo da regra quando ela não aparece como lei exterior, mas como o resultado de uma decisão livre porque mutuamente consentida. Evidentemente, cooperação e respeito mútuo são formas de equilíbrio ideais, que só se realizam através de conflito e exercício da democracia. O consentimento mútuo, o acordo de grupo determina as possibilidades de variação da regra. (Koudela, 2006, p. 49).

Sendo assim, o jogo teatral spoliniano foi um importante instrumento para que os/as participantes da oficina se permitissem fazer parte de um grupo, jogando com seus/suas parceiros/as, onde havia regras, mas que todos/as podiam ajudar a criar novas regras. Era o entendimento de pautas estabelecidas de conduta na oficina apresentadas para a promoção de conhecimento e não como processo de limitação ou repressão dialogando diretamente com as proposições de Spolin (2010).

Vasquez (2015) ainda em sua pesquisa sobre cultura prisional no Amapá, nos aponta que, sobre as regras do sistema, podemos entender que:

Por outro lado, a comprovação dessa realidade nos remete a compreender que o mundo da prisão é marcado ou caracterizado por um "sistema de valores" instituído e obedecidos pelos presos enquanto estão no cumprimento de suas penas, que por sua vez, compõe uma das mais variantes da cultura prisional. Com efeito, a descrição de algumas das "normas de convivência" estabelecida e vividas entre os grupos de cativos do instituto penitenciário pesquisado foram detalhadas no que foi possível pelos entrevistados [...] com o objetivo de exemplificar a subordinação dos presos ao poder prisional, além das tensões, violências e rigorosidades das "leis ou normas entre os grupos de cativos." (Vasques, 2015, p. 143).

Estas regras internas dialogaram com as regras da instituição: a orientação do projeto extensionista era a participação voluntária a partir do interesse individual. A determinação da instituição era a participação não condicionada à 
remissão de pena ou entendida em caráter de trabalho. A regra do grupo de participantes, tanto junto às mulheres quanto aos homens, era que as/os participantes se entregassem à proposta pois a mesma era uma oportunidade de ter momentos de socialização dentro do espaço prisional. Neste sentido, o jogo interno de regras (da instituição e da população carcerária) se fez presente, mas potencializado a partir da experiência que estavam vivenciando no/com o projeto.

Ao estar ministrando aulas na escola do sistema penitenciário, percebemos ao longo do tempo a existência de algumas regras de convivência que ecoavam nas oficinas de Teatro. O modo como são tratados/as os/as apenados/as a partir da abordagem dos/das agentes penitenciários/as reflete no que de fato é o sistema prisional. Era perceptível o desejo que aquelas pessoas possuíam para se expressar, opinar ou demonstrar suas sensações mais íntimas acerca do que trabalhamos. O projeto contribuiu para a melhoria em alguns aspectos pessoais por partes dos/as alunos/as oportunizando que as aulas de Teatro contribuíssem para a ampliação do olhar para com o sistema penitenciário e como cada ser presente naquele espaço, influencia o movimento deste. O Teatro despertou sentimentos adormecidos, responsabilidades, trocas de conhecimento e principalmente, mudanças pessoais individuais e coletivas no que tange o convívio em um grupo social.

Ao adentrar naquele espaço, percebeu-se que quando se perguntava ao grupo de participantes se já tinham tido acesso ao Teatro, dentro ou fora da prisão, quase todos/as respondiam que não. Poucos/as eram os/as que sabiam algo sobre o fazer teatral, como este ocorria e quais seus processos.

O sistema penitenciário propicia a/ao apenada/o nada mais nada menos do que tempo. Tempo este que faz vir à tona várias reflexões sobre si e sobre o espaço em que está inserido. A reclusão gera seres solitários e em muitos casos sem esperança ou ânimo para fazer algo fora de sua rotina já mecanizada. Por isso, muitas vezes ao adentrar na escola do sistema penitenciário, muitas/os não conseguiam se sentir livre o suficiente para participar das experimentações e jogos teatrais. Na instituição penitenciária possuem uma rotina programada: acordar, tomar café, realizar seus afazeres, almoçar, ir para a escola e depois voltar para a 
cela esperando um outro amanhecer.

A oficina de Teatro promovia então uma quebra nesta rotina oportunizando ao espaço prisional outras realizações dentro da própria rotina existente. Nas improvisações era possível transitar por diferentes espaços e épocas possibilitando ao corpo rememorar sensações ou experimentar aquelas ainda não sentidas. Neste processo gerador de vários trânsitos percebemos que:

O contato com corpos em privação de liberdade, a possibilidade de transgredir a lógica de instituições de controle, a liberdade que está sempre presente em toda e qualquer mente mesmo que o corpo físico esteja enclausurado, o trabalho que parte apenas de uma premissa: o interesse pessoal. Participa quem quer! Sem remição de pena. São fatores como estes que nos levaram ao sistema prisional, na cidade de Macapá e que se tornam materiais para desenharem a trajetória do projeto. Os corpos pulsantes nos mostraram que o foco se dá na transposição do processo de aprendizagem em teatro à vida diária, sem que a confecção do produto seja algo primordial. (Silva, ... [et al.], 2020, p. 123).

Assim, durante a trajetória do projeto, outras práticas para além daquelas já estabelecidas no que tange o funcionamento de um sistema penitenciário de forma geral, puderam ser proporcionadas à população carcerária promovidas pela Pedagogia Teatral.

Durante um ano, o projeto de extensão e o projeto de pesquisa foram realizados simultaneamente dentro do ambiente prisional em convívio direto com os apenados e as apenadas que estavam devidamente matriculados/as na escola presente no complexo penitenciário do Amapá. Diversas indagações surgiam constantemente. Diversas maneiras de ensinar e recriar a prática pedagógica em Teatro reverberaram no grupo propositor dos projetos apresentando questionamentos sobre como o Teatro pode ser uma vivência agregadora naquele lugar e elemento potencializador de autoconhecimento.

Nas diversas leituras dos/as teóricos/as aqui referenciados/as como base metodológica dos projetos no decorrer do processo de estudos, foi possível percebermos através de artigos sobre as relações entre Teatro e Prisão, que a presença das Artes da Cena em ambientes prisionais sempre foi um grande 
desafio. Desafio este que vai para além de um simples ensinar Teatro. É um ensinar voltado para a ressocialização destes indivíduos a partir de suas potencialidades.

Observamos que por vezes as pessoas em situação de cárcere aprendem a ler, escrever ou ter um contato maior com os saberes educacionais já dentro do ambiente prisional quando estes possuem escolas. Por isso, ações de Teatro junto a Educação Penitenciária se tornam metodologias potentes para a ampliação dos processos cognitivos destes indivíduos nestes espaços pois mobilizam saberes pedagógicos não só a nível profissional como pessoal. Ações como estas possibilitam processos de alfabetização não só educacional, mas estética, uma vez que, as oficinas de teatro ofertadas no ambiente carcerário:

Remetem-nos de algum modo a refletir sobre a experiência de transgressão, que pode aludir a aspectos negativos, como rebeldia, infração, violação e inobservância de normas, a qual é entendida na perspectiva da ação humana de atravessar e ultrapassar limites que solidificam a estrutura hierárquica na escola. (Ferreira, 2016, p. 2-3).

Durante todo o processo aqui relatado foi possível notar a diferença destes corpos no que tange a conscientização de cada participante para com sua própria imagem corporal. Trabalhar com o fazer teatral em um ambiente prisional não era nada fácil. Mas perceber como este mesmo fazer deve ser compartilhado às mais diferentes pessoas, era a motivação dos projetos e da formação discente/docente da equipe.

O Teatro propiciou a cada participante a capacidade de comunicar-se e expressar-se através dos jogos teatrais e sensoriais. Observar cada indivíduo naquele espaço possibilitou rever a construção docente que estamos construindo no curso de Licenciatura em Teatro da UNIFAP. Neste processo outro questionamento permeava a prática pedagógica proposta: Como o fazer teatral pode ser eficaz a ponto de cada indivíduo se ver de forma positiva consigo mesmo? Tentar responder o questionamento aqui apresentado foi uma busca constante nestes projetos.

Ao longo de meses, nas rotinas semanais de todas as terças e quintas-feiras, foram desenvolvidos jogos sensoriais e jogos teatrais que estimulavam a 
coletividade e troca. Teatro não se faz sozinho. Nem tão pouco somente a uma única forma. E no decorrer desse processo foi notável perceber que em pequenos atos, pequenas atitudes, aqueles/as alunos/as passaram a se comunicar de forma mais clara, a compartilhar experiências e a ver-se de forma diferente em relação ao contexto social. Os/As docentes da Escola Estadual São José também perceberam que os/as alunos/as passaram a demonstrar, a partir da experiência teatral, maior participação e iniciativa no ambiente escolar principalmente junto a disciplina Artes.

Todas as aulas eram construídas a partir das sugestões das/dos participantes registradas nos protocolos individuais de avaliação construídos ao final dos encontros. Um ponto de destaque foi sobre a questão do corpo em situação de cárcere:

Este corpo que na entrada dos aquecimentos era mais problemático, ou melhor, mais difícil, por ser um corpo que dorme em uma cela, precisa ter um tempo maior de preparo pois fica enrijecido, frio, das camas de concreto. (Silva, ... [et al.], 2020, p. 120-121).

O Teatro enquanto uma possibilidade de ressocialização, em especial no ambiente prisional, proporcionou a esses/as alunos/as a oportunidade de dialogar, comunicar e repensar a forma como se viam e como eram vistos/as naquele local.

\section{Da Extensão à Pesquisa em Teatro: A Experiência Formativa}

$\mathrm{O}$ ato de se repensar enquanto sujeito na sociedade aconteceu de forma cíclica reverberando na formação das/os bolsistas do projeto enquanto docentes e na análise dos processos vivenciados até o momento enquanto discentes, percebendo como o diálogo da Universidade para além de seu espaço físico oportuniza uma formação ampliada nas/os profissionais que a constitui.

A pesquisa oriunda da ação extensionista possibilitou averiguar como o Teatro com e a partir da comunidade pode aproximar as pessoas do fazer cultural, em específico o fazer teatral, mas criando oportunidades em que as Artes da Cena contribuam com o processo de ressignificação destes mesmos espaços como 
locais de discussão, deliberação, governança pública e de criação artística. A ressignificação do espaço escolar do sistema prisional e consequentemente da penitenciária como espaços possíveis de criação artística e não de reprodução artística, estabeleceu a pedagogia do Teatro como metodologia de empoderamento e autorreflexão pessoal e social.

Com estes projetos valida-se a importância e manutenção de ações de extensão e pesquisa em Teatro em espaços educativos presentes no sistema prisional por serem capazes de promoverem processos de empoderamento e de transposição do processo de aprendizagem para a vida diária (Spolin, 2010), entendendo que este pode também ser um local de práticas artísticas, culturais e de cidadania. Nos mostra também a necessidade de se ampliar a prática pedagógica em Teatro para diversos espaços uma vez que a pedagogia do Teatro é uma área de conhecimento capaz de efetivar "o princípio da indissociabilidade entre Ensino, Pesquisa e Extensão" que "deriva de demandas por mudanças necessárias acerca da função da Universidade - e do Ensino e da Pesquisa nela desenvolvidos, alçando ao mesmo status destes dois (não há hierarquia na Constituição)." (Gonçalves, 2015, p. 1231).

Esta experiência relatada se constitui como um caminho formativo potente na formação junto a prática pedagógica inclusiva em Teatro reforçando a necessidade do estudo das relações entre Artes da Cena e espaços de privação de liberdade demonstrando ainda como a pesquisa e a extensão promovem uma formação ampliada em discentes em contato com estes projetos, agregando conhecimentos a toda uma estrutura presente na matriz curricular dos cursos de graduação. Estes processos ampliados de formação são exemplos de como podemos exercer, seja como discentes e/ou docentes, a cidadania.

\section{Referências}

CONCÍLIO, Vicente. Teatro e Prisão - Dilemas da Liberdade Artística em Processos Teatrais com População Carcerária. Dissertação de Mestrado apresentada na ECA/USP, sob Orientação de Maria Lúcia de Souza Barros Pupo. São Paulo. 2006. 
FERREIRA, F. C. Pedagogia palhacesca: uma poética de atravessamentos, transgressões e comicidade na escola básica. 2016. (Mestrado Profissional em Arte) - Universidade Federal de Uberlândia, Uberlândia, 2016.

FREIRE, Paulo. Pedagogia do Oprimido. Rio de Janeiro: Paz e Terra, 1987.

GONÇALVES, Nadia Gaiofatto. Indissociabilidade entre Ensino, Pesquisa e Extensão: um princípio necessário. PERSPECTIVA, Florianópolis, v. 33, n. 3, p. 1229 - 1256, set./dez. 2015.

LIGIÉRO, Zeca. Teatro e comunidade: uma experiência. Uberlândia: Universidade Federal de Uberlândia, 1983.

KOUDELA, Ingrid Dormien. Jogos Teatrais. São Paulo: Perspectiva, 2006.

SILVA, Emerson de Paula...[et al.]. Trajetórias da pele: Teatro e educação penitenciária em Macapá. In: VASQUEZ, Eliane Leal; ABREU, Almiro Alves; FEIO, Leila do Socorro Rodrigues (Org.). Educação Penitenciária Amapaense: Pesquisas, demandas recorrentes e formulação de políticas educacionais. Uberlândia: Navegando Publicações, 2020. (Coleção Educar na Prisão e Escola, Vol. 1).

SPOLIN, Viola. Improvisação para o Teatro. Tradução e revisão Ingrid Dormien Koudela e Eduardo José de Almeida Amos. São Paulo: Perspectiva, 2010.

VASQUEZ, Eliane. Sociedade Cativa, entre cultura escolar e cultura prisional. 2 ed. Rio de Janeiro-RJ. Editor: George Martins, 2015.

Recebido em: 28/08/2020

Aprovado em: 26/10/2020 